\title{
The role of physical activity and heart rate variability for the control of work related stress
}

\author{
Laís Tonello ${ }^{1}$, Fábio B. Rodrigues ${ }^{1}$, Jeniffer W. S. Souza ${ }^{1}$, Carmen S. G. Campbell ${ }^{1}$, Anthony S. Leicht ${ }^{2}$ \\ and Daniel A. Boullosa ${ }^{1 *}$
}

${ }^{1}$ Department of Physical Education, Catholic University of Brasilia, Brasilia, Brazil

2 Institute of Sport and Exercise Science, James Cook University, Queensland, QLD, Australia

\section{Edited by:}

Arto J. Hautala, Verve Research,

Finland

\section{Reviewed by:}

Harri Lindholm, Finnish Institute of

Occupational Health, Finland

Arja L. T. Uusitalo, Helsinki

University Hospital, HUSLAB,

Finland

\section{*Correspondence:}

Daniel A. Boullosa, Post-Graduate

Program in Physical Education,

Catholic University of Brasilia, QS 07,

LT1 S/N - Sala 111 - Bloco G, Águas

Claras 71966-700, Brasilia, Brazil

e-mail:d_boullosa@yahoo.es
Physical activity (PA) and exercise are often used as tools to reduce stress and therefore the risk for developing cardiovascular diseases (CVD). Meanwhile, heart rate variability (HRV) has been utilized to assess both stress and PA or exercise influences. The objective of the present review was to examine the current literature in regards to workplace stress, PA/exercise and HRV to encourage further studies. We considered original articles from known databases (PubMed, ISI Web of Knowledge) over the last 10 years that examined these important factors. A total of seven studies were identified with workplace stress strongly associated with reduced HRV in workers. Longitudinal workplace PA interventions may provide a means to improve worker stress levels and potentially cardiovascular risk with mechanisms still to be clarified. Future studies are recommended to identify the impact of PA, exercise, and fitness on stress levels and HRV in workers and their subsequent influence on cardiovascular health.

Keywords: autonomic nervous system, physical fitness, exercise, allostatic load, employees

\section{INTRODUCTION}

The adaptive process by which an organism maintains homeostasis is known as allostasis with variable allostatic loads commonly experienced by humans (McEwen and Seeman, 1999; Frodl and O'Keane, 2012). When exposure to chronic stress becomes excessive, the allostatic load experienced may promote important alterations in stress sensitive systems that are intimately linked to the pathophysiology of many diseases (Juster et al., 2010). The most studied of all stress related disorders is cardiovascular disease (CVD), which has been highlighted as the leading cause of mortality worldwide (World Health Organization, 2011). Previously, stress experienced by a person at their place of employment or work has been suggested to substantially increase their CVD risk (Yarnell, 2008; Thayer et al., 2010) with the risk of coronary heart disease being increased by $50 \%$ among workers (Kivimaki et al., 2006). As individuals spend most of their daily time at work (e.g., $8-10 \mathrm{~h}$ per day), a greater examination of the impact of interventions focusing on managing work-related stress as an important component of allostatic loads is warranted to reduce CVD risk and promote life-long resiliency against abnormal allostatic loading for workers (Juster et al., 2010). Development of healthy workplaces and practices may provide important environments that combat chronic stress and its consequent adverse contribution to the increasing work-related development of disease (Taylor et al., 1997).

Physical activity (PA) and exercise have been extensively recognized as important influences on the relationship between psychosocial stress and CVD (Hamer, 2012) probably because of its influence on physical fitness. Thus, it would be expected that more active individuals, who conversely possess higher physical fitness, would be more resilient to mental stresses (Hamer, 2012). In this regard, interventions that involve PA in conjunction with other beneficial practices (e.g., social support) in the workplace may be very effective for the control of allostatic load at an individual level (Juster et al., 2010). However, the expected greater stress resilience in those individuals with a greater physical fitness has been questioned as the stress-buffering effect of physical fitness has not always been demonstrated (Jackson and Dishman, 2006). This lack of demonstration may be related to methodological constraints of previous studies (Hamer, 2012) with further studies warranted to elucidate the important role that PA and exercise could have on workers cardiovascular health, potentially as an important stress-buffer.

Heart rate variability (HRV) is an easy and non-invasive tool for the assessment of variations in beat-to-beat intervals and autonomic nervous system activity with HRV obtained by linear methods within the domains of time and frequency analyses, and nonlinear methods (Task Force, 1996). HRV has been studied extensively in regards to CVD (Vrijkotte et al., 2000; Kivimaki et al., 2006; Yarnell, 2008; Thayer et al., 2010; Frodl and O'Keane, 2012), exercise (Proper et al., 2002; Kiviniemi et al., 2007; Buchheit et al., 2010; Boullosa et al., 2012), and stress (Hjortskov et al., 2004; Collins et al., 2005; Yarnell, 2008; Loerbroks et al., 2010; Uusitalo et al., 2011). The use of HRV as a practical monitoring tool for allostatic load though has been scarce and may provide a simple instrument for workers in the workplace. Greater HRV has been related to lower cardiovascular risk (Kiviniemi et al., 2010), greater physical fitness and responsiveness to aerobic training (Hautala et al., 2010), greater PA levels in workers (Rennie et al., 2003), and lower 
work related stress in workers (Uusitalo et al., 2011). Collectively, these and other previous studies (Orsila et al., 2008; Thayer and Lane, 2009; Hynynen et al., 2011) emphasize the importance of HRV for the assessment of cardiovascular stress in the workplace with PA and fitness potentially enhancing HRV control. Therefore, the aim of this mini-review was to review the current literature regarding HRV, PA, fitness, and workplace stress to better delineate the current understanding and potential for future studies.

\section{MATERIALS AND METHODS}

An extensive search of relevant studies listed within the National Library of Medicine (PubMed) and ISI Web of Knowledge databases over the past 10 years (2003-2013) was conducted. The following combination of terms was utilized during the search: (exercise OR PA OR physical fitness) AND (workers OR occupational OR work OR job) AND cardiovascular stress (Figure 1). Inclusion criteria included: original articles; written in English; study population consisted of workers; included assessments of PA and/or exercise; assessment of work-related stress, and cardiac autonomic control monitored via HRV. The review, evaluation and selection of articles based upon inclusion criteria were carried out independently by three of the authors.

\section{RESULTS}

After initial searches based on the combination of specific terms were performed, there were 228 and 383 articles identified within PubMed and ISI Web of Knowledge databases, respectively (Figure 1). The titles and abstracts of these 611 articles were reviewed with 593 excluded as not meeting the inclusion criteria. Subsequently, 18 articles were obtained in full and examined further for details according to the inclusion criteria (Figure 1). Based upon these criteria, only seven articles were included in this study (see Table 1). These studies examined autonomic function via HRV for job stress evaluation, however studies included a variety of analyses, different scheduling of R-R recordings, and various populations that make comparisons difficult. Nevertheless, several studies (Chandola et al., 2008; Clays et al., 2011; Uusitalo et al., 2011) reported a reduced HRV in workers reporting workrelated stress. Interestingly, only Chandola et al. (2008) reported a positive association between work stress and CVD possibly as a consequence of the negative influence of stress on health behaviors (i.e., reduced PA and poor diet). Meanwhile, others (Eller

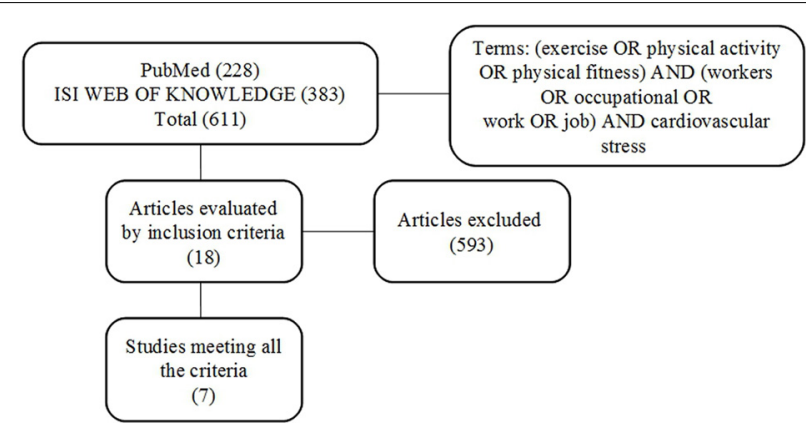

FIGURE 1 | Overview of search strategy. et al., 2011b; Lindholm et al., 2012) did not find any direct relationship between stress and HRV indices although a reduced HRV was exhibited during an imbalance between effort and reward, and in those workers experiencing irregular shiftwork, important sources of work-related stress. Likewise Melville et al. (2012) and Cheema et al. (2013) reported no relationship between HRV and stress with reductions in stress and anxiety following workplace yoga interventions accompanied by no changes in HRV.

All included studies assessed the level of PA or exercise with most simply reporting the level in a descriptive function. Only one study (Cheema et al., 2013) examined PA or exercise as an independent variable in a longitudinal design of work related stress and autonomic control of HR. Surprisingly, this recent study (Cheema et al., 2013) reported a worsening of autonomic control of HR (i.e., decrements in HRV indices) for the yoga intervention group vs. the control group. Paradoxically, the participants of this study exhibited improvements in some fitness characteristics and a reduced anxiety state after the yoga intervention suggesting an effective intervention but with an unexpected reduced HRV (Cheema et al., 2013). Previously, Melville et al. (2012) examined the acute effects of both yoga and meditation interventions on perceived stress and HRV with no significant changes in HRV during the acute post-intervention period (i.e., $15 \mathrm{~min}$ ), despite significant reductions in perceived stress after both interventions.

\section{DISCUSSION}

This review suggests that autonomic function could be a simple and effective measure to identify workplace stress. Additionally, a single study with longitudinal workplace PA interventions reported improved worker stress levels without significant positive changes in cardiac autonomic activity, a mechanism known to be cardioprotective. Based upon the current few studies of PA and stress, and equivocal relationships between stress and cardiovascular health in workers, we encourage more studies involving varying PA and exercise interventions in the workplace to better examine the benefits of PA and exercise on both stress and HRV.

Overall, the current review provides further support of the applicability of cardiac autonomic function monitoring for work related stress. Factors related to adverse working conditions such as excessive effort (Vrijkotte et al., 2004), effort-reward imbalance (Eller et al., 2011a; Uusitalo et al., 2011), over commitment (Vrijkotte et al., 2004; Lindholm et al., 2012), irregular shift work (Lindholm et al., 2012), and work stress (Chandola et al., 2008) were significantly related to reduced cardiac autonomic function. Therefore, HRV monitoring may provide a simple and non-invasive assessment of stress and allostatic load in working environments that employers could utilize in the efficient management of employees. The recent systematic review of Jarczok et al. (2013) provides further support for HRV use in employee management with adverse psychosocial work conditions reported to be negatively associated with autonomic nervous system function as indexed by HRV.

It should be pointed out that within the current review, a variety of different HRV analyses were employed that limited comparisons between studies. The selection of HRV methodology is an important issue as tool sensitivity may compromise 


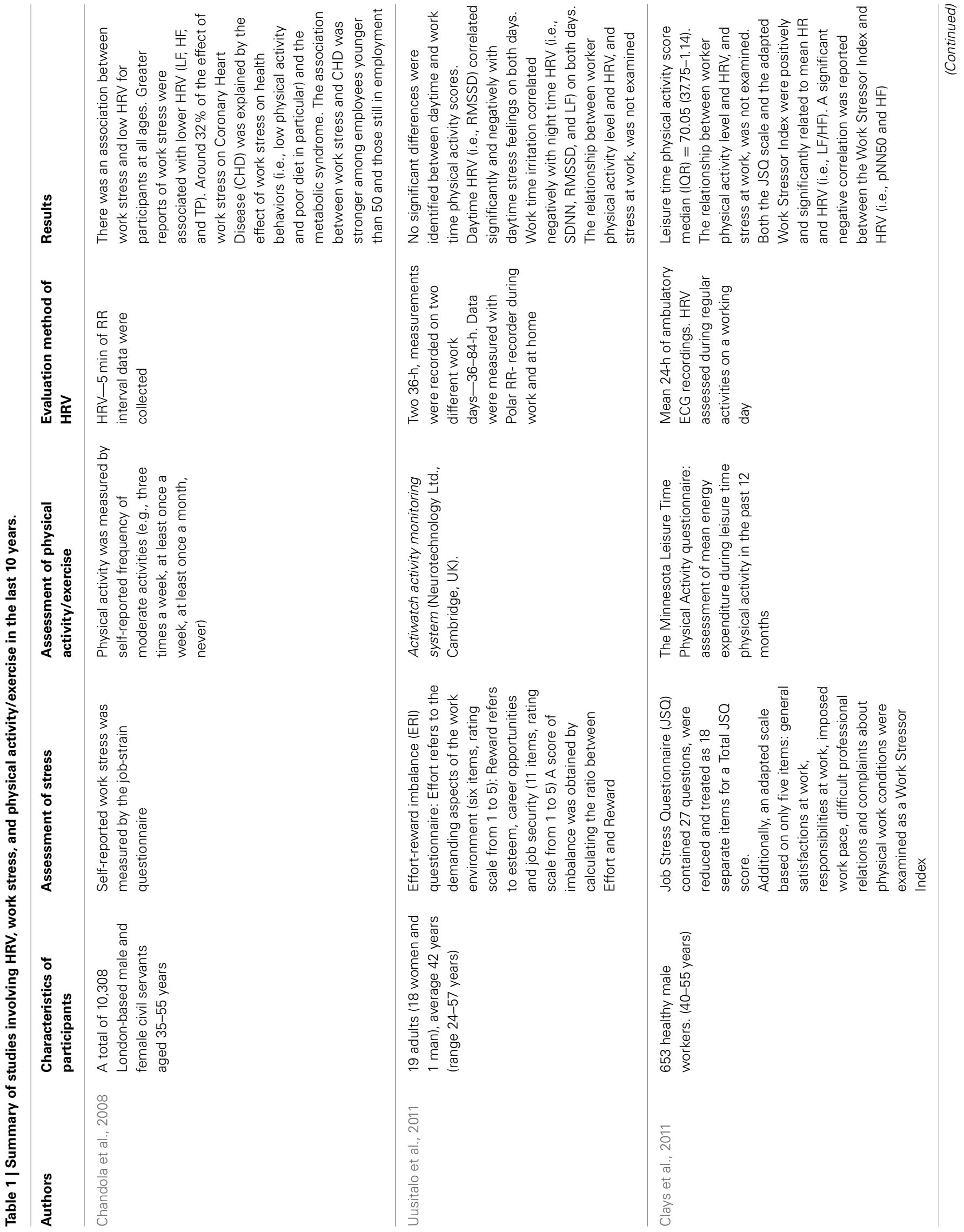




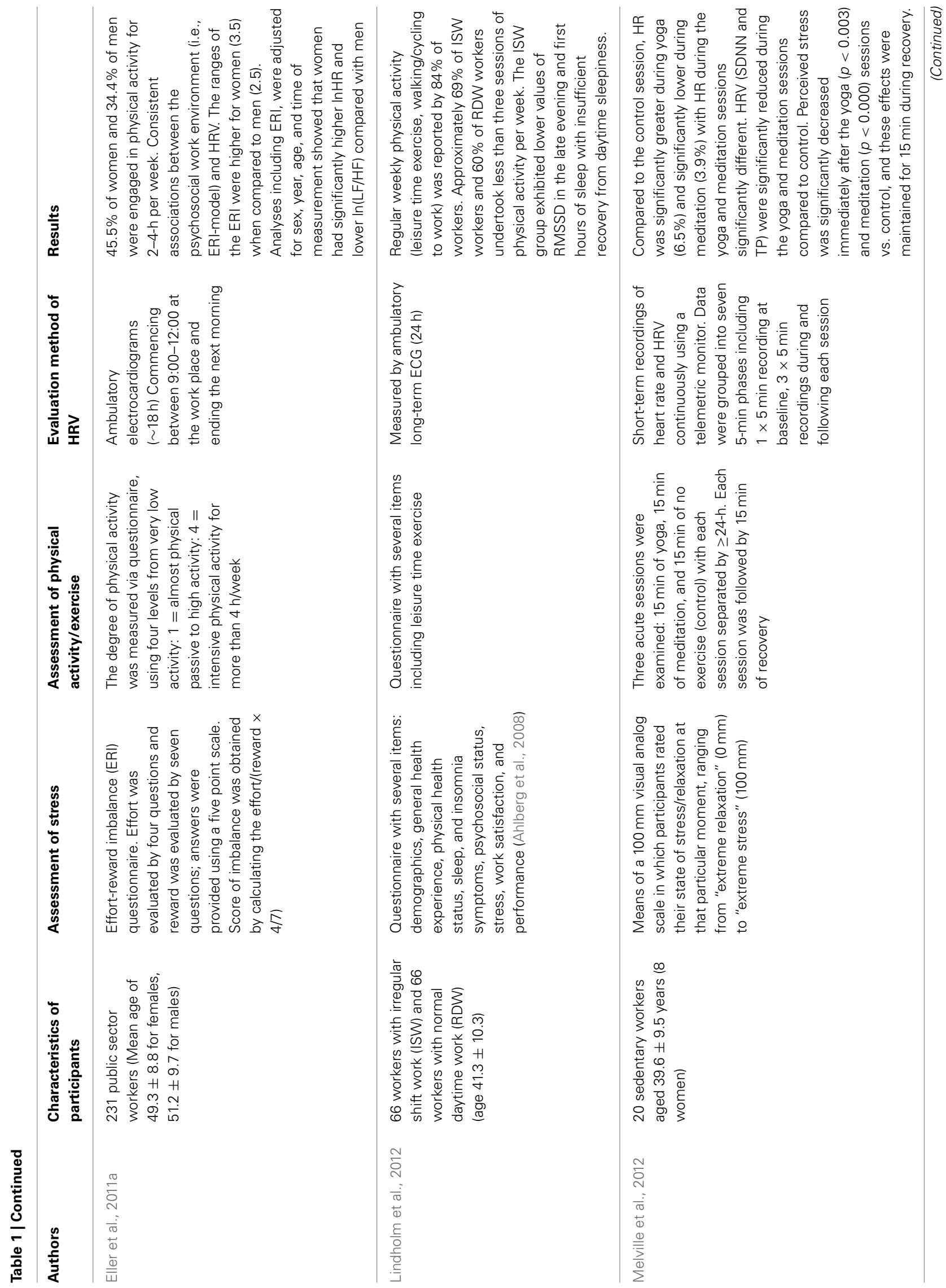




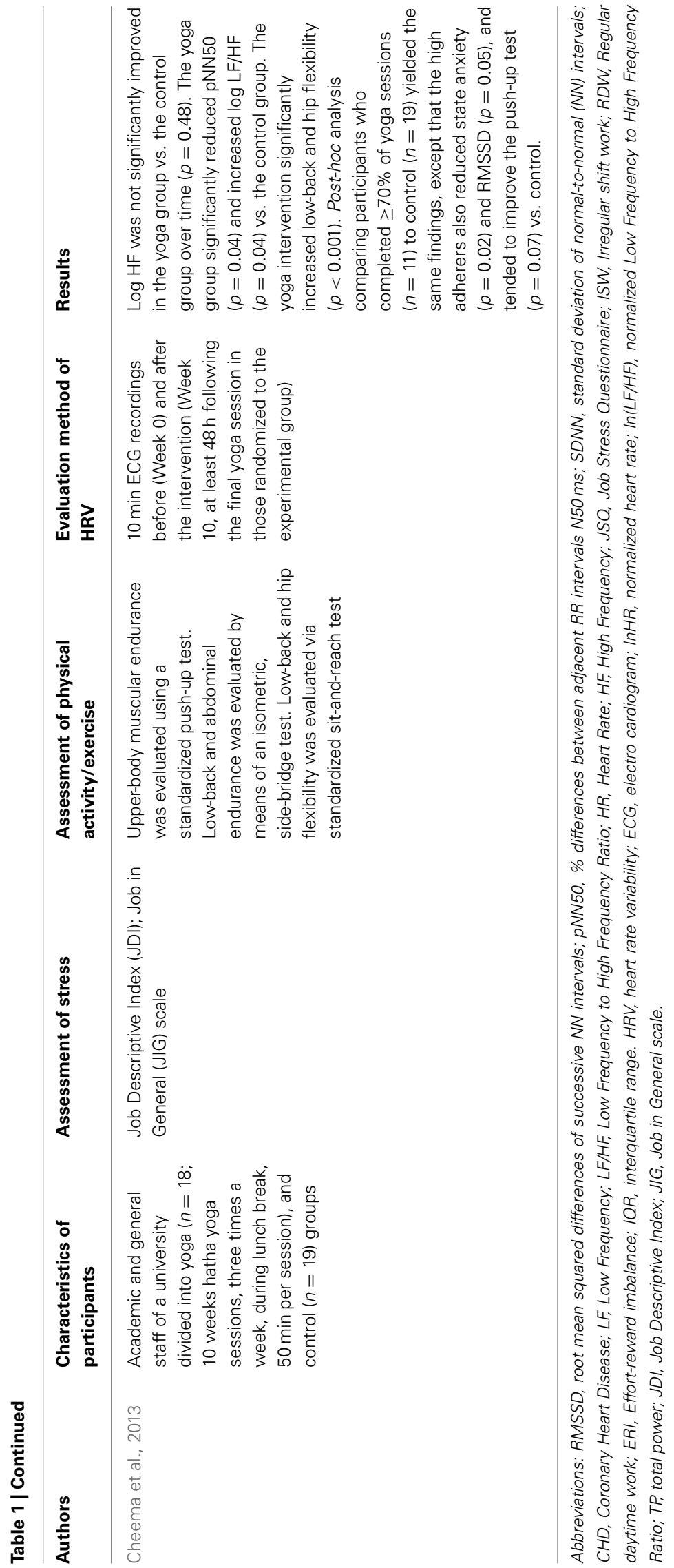


the detection of cardiac autonomic responses (Hynynen et al., 2011). Aspects such as variations in HRV measures examined (e.g., linear, non-linear, etc.), data analysis (e.g., supine, seated, Fast Fourier Transform, Autoregression, etc.) as well as the quality of data (e.g., degree of ectopy/artifact, sampling rate, recording length, etc.) make comparisons between studies challenging (Jarczok et al., 2013). For instance, Hynynen et al. (2011) reported that HRV during an orthostatic test upon wakening may be more useful for the analysis of stress in real life compared to night time recordings. In contrast, HRV measures recorded during both work and at night were reported to be also sensitive markers of mental stress alterations at work (Hjortskov et al., 2004; Yarnell, 2008). Further studies should determine the optimal HRV methods for detecting cardiac autonomic stress related adaptations. Factors such as the HRV measure (i.e., time or frequency domain, nonlinear, etc.), time, and duration of recordings and body posture (Young and Leicht, 2011; Boullosa et al., 2012) may play an important role that requires further clarification. Given the possible influence of factors external to work related stressors during long recordings, the use of laboratory controlled recordings should be included in further studies for a better evaluation of autonomic control of HR (Lombardi and Stein, 2011). Additionally, other cardiac autonomic indices (i.e., heart rate recovery; HRR, post-exercise) could also be employed as a delayed HRR was reported in individuals with high levels of stress and depression (Gordon et al., 2012). Consequently, the simple assessment of HRV and HRR may provide a comprehensive evaluation of the cardiac autonomic health of workers and prognosis for work-related stress and responsiveness to exercise training (Huovinen et al., 2011).

Another important restriction of studies within the current review was the different assessment tools for stress levels or psychosocial characteristics of work. For instance, the following tools were utilized in the current review studies: effort reward imbalance model (ERI-model) (Eller et al., 2011a; Uusitalo et al., 2011), Job Descriptive Index (JDI); Job in General (JIG) scale (Cheema et al., 2013), job stress questionnaire (Clays et al., 2011), stress questionnaire (Lindholm et al., 2012), job-strain questionnaire (Chandola et al., 2008), and a $100 \mathrm{~mm}$ visual analog scale (Melville et al., 2012). While each of the aforementioned tools has been used to assess stress at work, differences in specificity, reliability, and validity of these tools and their relationship with cardiac autonomic activity made comparisons difficult. Standardized use of stress assessment tools may help clarify the relationship between stress and cardiac autonomic activity. For example, Jarczok et al. (2013) highlighted that measurements of stress could be grouped when evaluated by ERI and JDC questionnaires with these questionnaires demonstrating a significant association between high strain/stress work and decreased vagal tone. Identification of the ultimate assessment tool may help to better understand the relationship between cardiovascular stress and workers health. Further, this tool may also overcome the confounding variables that affect the measurement of cardiac autonomic control such as age, sex, disease, caffeine intake, PA, smoking, and alcohol consumption (Jarczok et al., 2013).
One disappointing aspect of the current review was the low incidence of exercise and PA with only two studies involving exercise interventions (i.e., yoga or yoga and meditation) (Melville et al., 2012; Cheema et al., 2013) in the workplace. Further, these recent studies (Melville et al., 2012; Cheema et al., 2013) revealed contradictory results regarding the relationship between exercise interventions, stress, and HRV. The remaining studies (Vrijkotte et al., 2004; Clays et al., 2011; Eller et al., 2011a; Uusitalo et al., 2011; Lindholm et al., 2012) simply recorded PA as a factor of consideration in their analyses. Moreover, only one study objectively recorded the levels of PA via accelerometry (Uusitalo et al., 2011) with the remaining studies utilizing questionnaires for this purpose. Further, very few examined physical fitness with those studies assessing physical fitness (Clays et al., 2011; Uusitalo et al., 2011; Cheema et al., 2013) and not the potential role of this factor on stress responses and HRV. Therefore, the results of our review confirmed the variety of factors utilized in past studies with future studies recommended to examine objective measures of exercise and PA as these have been previously associated with HRV levels (Rennie et al., 2003; Hautala et al., 2010; Takada et al., 2010).

Previous studies have observed a weak and inverse association between job strain and leisure time PA indicating the potentially important role of PA for managing work related stress (Loerbroks et al., 2010). Previously, Choi et al. (2010) reported that having on-the-job learning opportunities and decision authority about their tasks may be conducive to increasing active leisure time PA in middle-aged US workers. While these previous studies have analyzed the impact of work conditions on leisure time PA, other studies have analyzed the impact of complex interventions including exercise in the workplace. For instance, Eriksen et al. (2002) previously demonstrated the greater effectiveness of complex interventions including PA than more focused non-PA interventions (e.g., stress management alone). Subsequently, Tveito and Eriksen (2009) reported in a randomized controlled study that a program consisting of physical exercise, stress management training, health information and an examination of the participants' workplace, promoted improvements in health, physical fitness, muscle pain, stress management, maintenance of health, and work situation. Overall, these previous studies highlighted the appropriateness of complex, exercise or PA based interventions at work for stress management and other health related outcomes. Paradoxically, in our focused review we found only two studies with workplace exercise interventions. Melville et al. (2012) evaluated the impact of a brief intervention (e.g., $15 \mathrm{~min}$ of yoga) at work on the acute cardiovascular responses (i.e., HR, $\mathrm{HRV}$, and blood pressure) and perceived stress. Interestingly, this study reported a higher HRV during yoga and meditation interventions that returned to baseline immediately after the session with a reduction of perceived stress for $15 \mathrm{~min}$ post-intervention (Melville et al., 2012). Although the results of this study were promising, these results, within a small time of evaluation, should be considered with caution, especially due to the low intensity and duration of yoga practice. However, such an exercise intervention could be promising for the control of acute workrelated stress responses (Hamer, 2012). Another study (Cheema et al., 2013) also evaluated the effectiveness of a workplace program based of hatha yoga ( 10 weeks, $50 \mathrm{~min}$ at lunch time, 3 
times per week) on physiological stress (HRV) and associated health-related outcomes in a cohort of office workers. Despite the reduction of anxiety and fitness improvements among those with high adherence rates, the decrease in HRV after the intervention period raised concerns about the effectiveness of this exercise modality for the cardiac health of workers. Further studies with other exercise and PA interventions, which are different concepts (Caspersen et al., 1985), may clarify the most appropriate modality and dose-response for the control of stress and associated CVD in workers.

In the current review, most studies were cross-sectional with only two involving exercise interventions (yoga and meditation). Based on this review, there is a notable lack of studies comparing longitudinal interventions and the cause-effect relationships between physical fitness, exercise, and PA, and cardiovascular stress (Hamer, 2012). Moreover, identification of barriers and facilitators for PA or exercise at work (Renton et al., 2011; Leicht et al., 2013) may assist with the development of the most appropriate interventions to assist workers based on their employment demands. For instance, emergency physicians with different shifts (14 or 24-h) exhibited significant differences in stress levels (Dutheil et al., 2012). Such factors may assist in developing the best interventions and any potential changes in working environments (Conn et al., 2009). Although the use of complex interventions including exercise, psychological and nutritional habits have been previously recommended (Carson et al., 2010; Strijk et al., 2012), the inclusion of sole exercise and/or PA interventions may determine the appropriate dose-response (Vanhees et al., 2012). This would be very important as the levels of physical fitness that protect against CVD when considering specific job demands remain undefined (Huang and Acevedo, 2011). Moreover, CVD risk factors and stress exhibit a bidirectional relationship as stress promotes changes in behavior and pathophysiological parameters and vice versa (Huang and Acevedo, 2011) that should be considered in both prevention and treatment interventions (Stults-Kolehmainen, 2013). Thus, stressed workers may be less inclined to perform PA contributing to a greater deterioration of their health and progression of pathophysiological conditions (Azevedo et al., 2012; Silva and Barreto, 2012). Identification of barriers and motivators within workers would be an important aspect for designing effective and individualized intervention programs that also considers PA levels and sitting time derived from specific job activities (Leicht et al., 2013).

In summary, the results of the current review suggested a relationship between work related stress and autonomic control of HR. However, the extent of the positive benefits of both PA and exercise on both stress and HRV remains to be elucidated. Thus, future research, especially longitudinal studies, with different work categories and samples are needed to better understand how different levels of physical fitness, energy expenditure and exercise modes prevent or minimize the allostatic load and subsequent stress on workers and their impact on cardiovascular health.

\section{ACKNOWLEDGMENTS}

Laís Tonello was partially supported by a scholarship from CNPq.

\section{REFERENCES}

Ahlberg, K., Jahkola, A., Savolainen, A., Kononen, M., Partinen, M., Hublin, C., et al. (2008). Associations of reported bruxism with insomnia and insufficient sleep symptoms among media personnel with or without irregular shift work. Head Face Med. 28, 4. doi: 10.1186/1746-160X-4-4

Azevedo, S. M., Singh-Manoux, A., Brunner, E. J., Kaffashian, S., Shipley M. J., and Kimimaki M. (2012). Bidirectional association between physical activity and symptoms of anxiety and depression: the whitehall II study. Eur. J. Epidemiol. 27, 537-546. doi: 10.1007/s10654-012-9692-8

Boullosa, D. A., Abreu, L., Tuimil, J. L., and Leicht, A. S., (2012). Impact of a soccer match on the cardiac autonomic control of referees. Eur. J. Appl. Physiol. 112, 2233-2242. doi: 10.1007/s00421-011-2202-y

Buchheit, M., Mendez-Villanueva, A., Quoud, M. J., Poulos, N., and Bourdon, P. (2010). Determinants of the variability of heart rate measures during a competitive period in young soccer players. Eur. J. Appl. Physiol. 109, 869-878. doi: 10.1007/s00421-010-1422-x

Carson, R. L., Baumgartner, J. J., Matthews, R. A., and Tsouloupas, C. N. (2010). Emotional exhaustion, absenteeism, and turnover intentions in childcare teachers: examining the impact of physical activity behaviors. J. Health Psychol. 15, 905-914. doi: 10.1177/1359105309360697

Caspersen, C. J., Powell, K. E., and Christenson, G. M. (1985). Physical activity, exercise, and physical fitness: definitions and distinctions for health-related research. Public Health Rep. 100, 126-131.

Chandola, T., Britton. A., Brunner, E., Hemingway, H., Malik, M., Kumari, M., et al. (2008). Work stress and coronary heart disease: what are the mechanisms? Eur. Heart J. 29, 640-648. doi: 10.1093/eurheartj/ehm584

Cheema, B. S., Houridis, A., Busch, L., Raschke-Cheema, V., Melville, G. W., Marshall, P. W., et al. (2013). Effect of an office worksite-based yoga program on heart rate variability: outcomes of a randomized controlled trial. BMC Complement. Altern. Med. 13:82. doi: 10.1186/1472-6882

Choi, B., Schnall, P. L., Yang. H., Dobson, M., Landsbergis, P., Israel, L., et al. (2010). Psychosocial working conditions and active leisure-time physical activity in middle-aged us workers. Int. J. Occup. Med. Environ. Health 23, 239-253. doi: 10.2478/v10001-010-0029-0

Clays, E., Bacquer, D. D., Crasset, V., Kittel, F., Smet, P., Kornitzer, M., et al. (2011). The perception of work stressors is related to reduced parasympathetic activity. Int. Arch. Occup. Environ. Health 84, 185-191. doi: 10.1007/s00420010-0537-z.

Collins, S. M., Karasek, R. A., and Costas, K. (2005). Job strain and autonomic indices of cardiovascular disease risk. Am. J. Ind. Med. 48, 182-193. doi: 10.1002/ajim.20204

Conn, V. S., Hafdahl, A. R., Cooper, P. S., Brown, L. M., and Lusk, S. L. (2009). Meta-analysis of workplace physical activity interventions. Am. J. Prev. Med. 37, 330-339. doi: 10.1016/j.amepre.2009.06.008

Dutheil, F., Boudet, G., Lac, G., Ouchchane, L., Chamous, A., Duclos, M., et al. (2012). Jobstress study: comparison of heart rate variability in emergency physicians working a 24-hour shift or a 14-hour night shift-a randomized trial. Int. J. Cardiol. 158, 322-325. doi: 10.1016/j.ijcard.2012.04.141

Eller, N. H., Blod, M., Nielsen, M., Kristiansen, J., and Netterstrom, B. (2011a). Effort reward imbalance is associated with vagal withdrawal in danish public sector employees. Int. J. Psychophysiol. 81, 218-224. doi: 10.1016/j.ijpsycho.2011.06.014

Eller, N. H., Kristiansen, J., and Hansen, A. M. (2011b). Long-term effects of psychosocial factors of home and work on biomarkers of stress. Int. J. Psychophysiol. 79, 195-202. doi: 10.1016/j.ijpsycho.2010.10.009

Eriksen, H. R., Ihlebaek, C., Mikkelsen, A., Grønningsaeter, H., Sandal, G. M., and Ursin, H. (2002). Improving subjective health at the worksite: a randomized controlled trial of stress management training, physical exercise and an integrated health programme. Occup. Med. 52, 383-391. doi: $10.1093 /$ occmed/52.7.383

Frodl, T., and O'Keane, V. (2012). How does the brain deal with cumulative stress? a review with focus on developmental stress, HPA axis function and hippocampal structure in humans. Neurobiol. Dis. 52, 24-37. doi: 10.1016/j.nbd. 2012.03.012

Gordon, J. L., Ditto, B., and Antono, B. D. (2012). Cognitive depressive symptoms associated with delayed heart rate recovery following interpersonal stress in healthy men and women. Psychophysiology 49, 1082-1089. doi: 10.1111/j.14698986.2012.01397.x 
Hamer, M. (2012). Psychosocial stress and cardiovascular disease risk: the role of physical activity. Psychosom. Med. 74, 896-903. doi: 10.1097/PSY.0b013 e31827457f4

Hautala, A. J., Karjalainen, J., Kiviniemi, A. M., Kinnunen, H.,Mäkikallio, T. H.,Huikuri, H. V.,et al. (2010). Physical activity and heart rate variability measured simultaneously during waking hours. Am. J. Physiol. Heart Circ. Physiol. 298, 874-880. doi: 10.1152/ajpheart.00856.2009

Hjortskov, N., Rissén, D., Blangsted, A. K., Fallentin, N., Lundberg, U., and Sogaard, K. (2004). The effect of mental stress on heart rate variability and blood pressure during computer work. Eur. J. Appl. Physiol. 92, 84-89. doi: 10.1007/s00421-004-1055-Z

Huang, C. J., and Acevedo, E. O. (2011). Occupational Stress: the influence of obesity and physical activity/fitness on immune function. Occup. Stress. 5, 486-493. doi: $10.1177 / 1559827611418168$

Huovinen, J., Kyrolainen, H., Linnamo, V., Tanskanen, M., Kinnunen, H., Hakkinen, K., et al. (2011). Cardiac autonomic function reveals adaptation to military training. Eur. J. Sport Sci. 11, 231-240. doi: 10.1080/17461391.2010.506659.

Hynynen, E., Konttinen, N., Kinnunen, U., Kyrolainen, H., and Rusko, H. (2011). The incidence of stress symptoms and heart rate variability during sleep and orthostatic test. Eur. J. Appl. Physiol. 111, 733-741. doi: 10.1007/s00421-0101698-x

Jackson, E. M., and Dishman, R. K. (2006) Cardiorespiratory fitness and laboratory stress: a meta-regression analysis. Psychophysiology 43, 57-72. doi: 10.1111/j.1469-8986.2006.00373.x

Jarczok, M. N., Jarczok. M., Mauss, D., Koenig, J., Li, J., Herr, R. M., et al. (2013). Autonomic nervous system activity and workplace stressors - a systematic review. Neurosci. Biobehav. Rev. 37, 1810-1823. doi: 10.1016/j.neubiorev.2013.07.004

Juster, R. P., McEwen, B. S., and Lupien, S. J. (2010). Allostatic load biomarkers of chronic stress and impact on health and cognition. Neurosci. Biobehav. Rev. 35 , 2-16. doi: 10.1016/j.neubiorev.2009.10.002

Kivimaki, M., Virtanen, M., Elovainio, M., Kouvonen, A., Vaananen, A. J., and Vahtera, J. (2006). Work stress in the etiology of coronary heart disease A meta-analysis. Scand. J. Work Environ. Health. 32, 431-442. doi: 10.5271/ sjweh.1049

Kiviniemi, A. M., Hautala, A. J., Kinnunen, H., Nissila, J., Virtanen, P., Karjalainen, J., et al. (2010). Daily exercise prescription on the basis of HR variability among men and women. Med. Sci. Sports Exerc. 42, 1355-1363. doi: 10.1249/MSS.0b013e3181cd5f39

Kiviniemi, A. M., Hautala, A. J., Kinnunen, H., and Tulppo, M. P. (2007). Endurance training guided individually by daily heart rate variability measurements. Eur. J. Appl. Physiol. 101, 743-751. doi: 10.1007/s00421-0070552-2

Leicht, A. S., Sealey, R. M., and Devine, S. (2013). Relationship between employment category and gender on quality of life, physical activity and their barriers and motivators, for full-time University staff. Int. J. Workplace Health Manage. 6, 160-173. doi: 10.1108/IJWHM-042012-0008

Lindholm, H., Sinisalo, J., Ahlberg, J., Hirvonen, A., Hublin, C., Partinen, M., et al. (2012). Attenuation of vagal recovery during sleep and reduction of cortisol/melatonin ratio in late afternoon associate with prolonged daytime sleepiness among media workers with irregular shift work. Am. J. Ind. Med. 55, 643-649. doi: 10.1002/ajim.22042

Loerbroks, A., Schilling, O., Haxsen, V., Jarczok, M. N., Thayer, J. F., and Fischer, J. E. (2010). The fruits of ones labor: Effort-reward imbalance but not job strain is related to heart rate variability across the day in 35-44year-old workers. J. Psychosom. Res. 69, 151-159. doi: 10.1016/j.jpsychores. 2010.03.004

Lombardi, F., and Stein, P. K. (2011) Origin of heart rate variability and turbulence: an appraisal of autonomic modulation of cardiovascular function. Front. Physiol. 2:95. doi: 10.3389/fphys.2011.00095

McEwen, B. S., and Seeman, T. (1999). Protective and damaging effects of mediators of stress. elaborating and testing the concepts of allostasis and allostatic load. Ann. N.Y Acad. Sci. 896, 30-47. doi: 10.1111/j.1749-6632.1999. tb08103.x

Melville, G. W., Chang, D., Colagiuri, B., Marshall, P. W., and Cheema,B. S. (2012). Fifteen minutes of chair-based yoga postures or guided meditation performed in the office can elicit a relaxation response. Evid.
Based Complement. Alternat. Med. 2012, 501986. doi: 10.1155/2012/ 501986

Orsila, R., Virtanen, M., Luukkaala, T., Tarvainon, M., Karjalainen, P., Viik, J., et al. (2008). Perceived mental stress and reactions in heart rate variability - a pilot study among employees of an electronics company. Int. J. Occup. Saf. Ergon. 14, 275-283. Available online at: http://www.ciop.pl/27071

Proper, K. I., Staal, B. J., Hildebrandt, V. H., Van Der Beek, A. J., and Van Mechelen, W. (2002). Effectiveness of physical activity programs at worksites with respect to work-related outcomes. Scand. J. Work Environ. Health. 28, 75-84. doi: $10.5271 /$ sjweh.651

Rennie, K. L., Hemingway, H., Kumari, M., Brunner, E., Malik, M., and Marmot, M. (2003). Effects of moderate and vigorous physical activity on heart rate variability in a British study of civil servants. Am. J. Epidemiol. 158, 135-143. doi 10.1093/aje/kwg120

Renton, S. J., Lightfoot, N. E., and Maar, M. A. (2011). Physical activity promotion in call centres: employers' perspectives. Health Educ. Res. 26, 1050-1059. doi: 10.1093/her/cyr055

Silva, L. S., and Barreto, S. M. (2012). Averse phycosocial working conditions and poor quality of life among financial servisse employees in Brazil. J. Occup. Health. 54, 88-95. doi: 10.1539/ joh.11-0072-OA

Strijk, J. E., Proper, K. I., van der Beek, A. J., and van Mechelen, W. (2012). A worksite vitality intervention to improve older workers' lifestyle and vitality - related out comes: results of a randomized controlled trial. J. Epidemiol. Community Health. 66, 1071-1078. doi: 10.1136/jech-2011200626

Stults-Kolehmainen, M. A. (2013). The interplay between stress and physical activity in the prevention and treatment of cardiovascular disease. Front. Physiol. 4:346. doi: $10.3389 /$ fphys.2013.00346

Takada, M., Ebara, T., and Kamijima, M. (2010). Heart rate variability assessment in Japanese workers recovered from depressive disorders resulting from job stress: measurements in the workplace. Int. Arch. Occup. Environ. Health. 83, 521-529. doi: 10.1007/s00420-0090499-1

Task Force of the European Society of Cardiology and the North American Society of Pacing and Electrophysiology. (1996). Heart rate variability. Standards of measurement, physiological interpretation, and clinical use. Circulation 93, 1043-1065. doi: 10.1161/01.CIR. 93.5.1043

Taylor, S. E., Repetti, R. L., and Seeman, T. (1997). Health psychology: what is an unhealthy environment and how does it get under the skin? Annu. Rev. Psychol. 48, 411-447. doi: 10.1146/annurev.psych. 48.1.411

Thayer, J. F., and Lane, R. D. (2009). Claude Bernard and the heart brain connection: further elaboration of a model of neurovisceral integration. Neurosci. Biobehav. Rev. 33, 81-88. doi: 10.1016/j.neubiorev.2008. 08.004

Thayer, J. F., Yamamoto, S. S., and Brosschot, J. F. (2010). The relationship of autonomic imbalance, heart rate variability and cardiovascular disease risk factors. Int. J. Cardiol. 141, 122-131. doi: 10.1016/j.ijcard.2009. 09.543

Tveito, T. H., and Eriksen, H. R. (2009). Integrated health programme: a workplace randomized controlled trial. J. Adv. Nurs. 65, 110-119. doi: 10.1111/j.13652648.2008.04846.x

Uusitalo, M. T., Martinmaki, K., Mauno, S., Kinnunen, U., and Rusko, H. (2011). Heart rate variability related to effort at work. Appl. Ergon. 42, 830-838. doi: 10.1016/j.apergo.2011.01.005

Vanhees, L., Geladas, N., Hansen, D., Kouidi, E., Niebauer, J., Reiner, Z., et al. (2012). Importance of characteristics and modalities of physical activity and exercise in the management of cardiovascular health in individuals with cardiovascular risk factors: recommendations from the EACPR. Part II. Eur. J. Prev. Cardiol. 19, 1005-1033. doi: 10.1177/1741826 711430926

Vrijkotte, T. G., Van Doornen, L. J., and De Geus, E. J. (2004). Overcommitment to work is associated with changes in cardiac sympathetic regulation. Psychosom. Med. 66, 656-663. doi: 10.1097/01.psy.0000138283. 65547.78

Vrijkotte, T. G. M., van Doornen, L. J. P., and de Geus, E. J. C. (2000). Effects of work stress on ambulatory blood pressure, heart rate, and 
heart rate variability. Hypertension 35, 880-886. doi: 10.1161/01.HYP. 35.4 .880

World Health Organization. (2011). Global Status Report on Noncommunicable Diseases 2010. Geneva.

Yarnell, J. (2008). Stress at work-an independent risk factor for coronary heart disease? Eur. Heart J. 29, 579-80. doi: 10.1093/eurheartj/ ehm641

Young, F. L., and Leicht, A. S. (2011). Short-term stability of resting heart rate variability: influence of position and gender. Appl. Physiol. Nutr. Metab. 36, 210-218. doi: 10.1139/h10-103.

Conflict of Interest Statement: The authors declare that the research was conducted in the absence of any commercial or financial relationships that could be construed as a potential conflict of interest.
Received: 30 October 2013; accepted: 04 February 2014; published online: 21 February 2014.

Citation: Tonello L, Rodrigues FB, Souza JWS, Campbell CSG, Leicht AS and Boullosa DA (2014) The role of physical activity and heart rate variability for the control of work related stress. Front. Physiol. 5:67. doi: 10.3389/fphys.2014.00067

This article was submitted to Clinical and Translational Physiology, a section of the journal Frontiers in Physiology.

Copyright (C) 2014 Tonello, Rodrigues, Souza, Campbell, Leicht and Boullosa. This is an open-access article distributed under the terms of the Creative Commons Attribution License (CC BY). The use, distribution or reproduction in other forums is permitted, provided the original author(s) or licensor are credited and that the original publication in this journal is cited, in accordance with accepted academic practice. No use, distribution or reproduction is permitted which does not comply with these terms. 